second regression analysis were associated with the rating-scale predictors, "secure-insecure" and "reliable-unreliable." The point here is that inferences about the personal security and reliability of the stimulus person involved going beyond the information given, since it may be recalled that the stimulus person was represented solely by information conceming dominance, orderliness, and affiliation. Such a liberal inference style is characteristic of people with complex conceptual systems (Schroder et al, 1967).

\section{REFERENCES}

ASCH, S. E. Forming impressions of personality. Journal of Abnormal \& Social Psychology, $1946,41,258-290$.

HESS, E. H., \& POLT, J. M. Pupil size in relation to mental activity during simple problem solving. Science, 1964, 143, 1190-1192.

JACKSON, D. N. Personality research form manual Goshen, N.Y.: Research Psychologists Press, 1967.

KAHNEMAN, D., \& BEATTY, J. Pupil diameter and load on memory. Science, 1966, 154, 1583-1585.

LAY, C. H., \& JACKSON, D. N. An analysis of the generality of trait inferential networks. Journal of Personality \& Social Psychology, 1969, 12 , 12-21.

PAIVIO, A. Personality and audience influence. In
B. A. Maher (Ed.), Progress in experimental personality research. Vol. 2. New York: Academic Press, 1965.

PAIVIO, A., \& SIMPSON, H. M. The effect of word abstractness and pleasantness on pupil size during an imagery task. Psychonomic Science, 1966, 5, 55-56.

PYLYSHYN, Z. W. Clinical correlates of some syntactic features of patients' speech. Research Bulle tin No. 41, University of Westem Ontario, London, 1967.

SHRODER, H. M., DRIVER, M. J., \& STREUFERT, S. Human information processing. New York: Holt, Rinehart, \& Winston, 1967.

SIMPSON, H. M., \& PAIVIO, A. Effects on pupil size of manual and verbal indicators of cognitive task fulfillment. Perception \& Psychophysics, 1968, 3, 185-190.

TEPLOV, B. M. Problems in the study of general types of higher nervous system activity in man and animals. In J. A. Gray (Ed.), Pavlov's typology. Oxford: Pergamon Press, 1964. Pp. 3-158.

\section{NOTES}

1. This research was partially supported by Canada Council Grant 68-0667 to the first author, and National Research Council Grant AP-304 to the second author, and by the University of Westem Ontario Research Fund.

2. Simpson, H. M. Personal communication. Mean pupillary dilation during a standard cognitive task was significantly larger for a group of high audience-sensitive $S s$ than for low audience-sensitive Ss equated for IQ.

\title{
Cooperation and sharing behavior among culturally deprived preschool children
}

BARBARA H. WASIK, S. KATHY SENN, and ALEX EPANCHIN, Education Improvement Program, Duke University, Durham, N.C. 27706

Culturally deprived Negro and white kindergarten children $(N=12)$ were paired in like-sex dyads to investigate cooperative and sharing behavior. The development of cooperative behavior was demonstrated in a game situation in which the children received a marble for cooperative responses. Selfish behavior was analyzed using two different definitions which resulted in varying per cents of selfish behavior. A discussion of the disparities ensued.

According to different investigators, preschool children, when given an opportunity to divide objects between themselves and a second person, have demonstrated selfish behavior. That is, they retained more items for themselves than they gave to another child (Ugurel-Semin, 1952; Handlon \& Gross, 1959). To arrange a possible sharing situation, Handlon \& Gross (1959) had dyads of preschool- and elementary-age children play a game in which they were required to cooperate in order to receive a seal. After the children received a specified odd number of seals, each was asked to divide the seals between himself and the other child. The preschool children demonstrated selfish behavior by retaining a mean of $72 \%$ of the seals. The selfish behavior demonstrated by the older children continually declined. Using 4 - to 16-year-old children, Ugurel-Semin (1952) had each child divide an odd number of nuts with another child. On $67 \%$ of the trials, 4 to 6-year-old children showed selfish behavior by keeping more nuts than they gave to the other child. Older children showed less selfish behavior.

In arranging an experiment to study sharing and cooperation behavior among children, it was difficult to interpret research findings such as those above because of differences in definitions and procedures. Although Handlon \& Gross (1959) and Ugurel-Semin (1952) both found preschool children to demonstrate selfish behavior, each gave percentages that represented different experimental definitions of selfish behavior. Handlon \& Gross (1959) defined selfish behavior as the percentage of items kept by the child, while Ugurel-Semin (1952) defined it as the percentage of trials that the $S$ kept more items than he gave to the other child. These two definitions can yield different percentages for the same data and, thus, imply varying results.

Although Handlon \& Gross (1959) required cooperation in a game to lead to the sharing situation, they did not investigate aspects of cooperative behavior. Es such as Azrin \& Lindsley (1956) and Brotsky \& Thomas (1967) have studied cooperative behavior between children in a game situation, but have not studied sharing behavior. Azrin \& Lindsley (1956) demonstrated the development of a cooperative response in children from 7 to 12 years old by requiring two children, who were seated facing each other, to place styli in directly opposite holes within $.04 \mathrm{sec}$ of each other. If successfully completed, a light flashed and a jelly bean dropped into a receptacle between them. Using preschool children, Brotsky \& Thomas (1967) attempted to develop a cooperative response similar to that developed by Azrin \& Lindsley (1956). To cooperate, the children had to press knobs of the same color. A buzz, a light, and an edible treat followed each cooperative response. Although cooperative responses increased, noncooperative responses also increased, and the Es concluded that the children were learning an operant response of "knob pressing" rather than the cooperative response.

The purpose of this study was to arrange a task in which cooperative responses in culturally deprived preschool children could be assessed and sharing of the earned reinforcement could be investigated. Negro and white children were used as $S s$, with like-sex Ss paired in an experimental game. Sharing behavior was analyzed both by the Handlon \& Gross (1959) and the Ugurel-Semin (1952) definitions.

\section{SUBJECTS AND APPARATUS}

The $12 \mathrm{Ss}$ were enrolled in a summer kindergarten for culturally disadvantaged children. Ss, ranging in age from 5.5 to 6.5 years, were randomly selected to fill the squares in a balanced race by sex design. Each $S$ played the game five times, each time with a different partner of the same sex. Within the like-sex groups, all possible combinations of $\mathrm{Ss}$ were used.

The apparatus consisted of two small flat blocks placed on opposite sides of a table. Each block had two button-operated switches, one white switch and either a red or blue switch. On the wall, $2 \mathrm{ft}$ above the experimental table, were the three lights colored red, white, and blue. Seating positions at the side with the red or blue switch were balanced.

Whenever the red switch or the blue switch was pressed, the matching colored light came on for $1 \mathrm{sec}$. When the white switches were pressed simultaneously, the white light came on for $3 \mathrm{sec}$, and a marble rolled into a box in the center of the table. The marbles were dispensed into the room 
through a tube from a Davis Scientific Instruments universal feed, situated in an adjoining control room.

When a pair of Ss was brought into the experimental room, $E$ gave the following instructions:

You are going to play a game together. Each of you has two buttons. You [to S1] have a red one and a white one, and you [to S2] have a blue one and a white one. When the game starts, you can press either button. Sometimes when you press a button, a light will come on. Sometimes when you press a button, a light will come on and you will also receive a marble. You have to press buttons to be able to get marbles. See how many you can get together. If you earn some marbles, you will be able to keep some for yourself.

Remember, you have to press your button to make a light come on or to get a marble.

The pair was allowed to play the game until they received nine marbles or until $7 \mathrm{~min}$ had expired. The number of presses, duration of presses, and the presentation times of lights and marbles were recorded on an Esterline-Angus event recorder.

At the end of the game, the Ss were taken into separate rooms. Each child was accompanied by an adult $\mathrm{E}$, who had with her nine marbles in two cups. E said: "You and earned these marbles. Since the two of you earned them, you may keep them. Put the ones for __ in this cup, and the ones for you in that cup." Each $S$ was allowed to keep the number of marbles he allotted to himself. The marbles were placed in a paper bag, and the child picked them up after school.

\section{RESULTS}

The cooperative and noncooperative responses were analyzed in a four-way analysis of variance, with cooperative-noncooperative responses, race, sex, and trials as variables. Because of missing data for some trials, the data within the cells of the design were pooled over Ss, thus providing one measure per cell. It was hypothesized that there would be no significant three-way interactions. Thus, following a procedure described by Winer (1962), the three-way interaction effects were tested using the four-way interaction as an estimate of error. Since no significant three-way interactions were found, the three- and four-way interactions were pooled to provide the error term for the analysis.

There was a signiticant outton errect, with the children responding more on the cooperative button than on the noncooperative button $(F=72.30$, $\mathrm{df}=1 / 17, p<.01$ ). The main effects of sex and race were also significant (sex: $F=4.66$, df $=1 / 17, \quad p<.05 ;$ race: $F=7.22$, $\mathrm{df}=1 / 17, \mathrm{p}<.05)$. The trials effect was not significant at the $5 \%$ level, and none of the two-way interactions were significant.

The total trial time (amount of time to receive nine marbles) was analyzed separately for each sex in a one-way analysis of variance. For the girls, two dyads failed to earn nine marbles in the allotted $7 \mathrm{~min}$, and their data were deleted from the following analysis. The results of the analysis of variance on dyad trial time for the boys and girls showed that race (white, Negro, mixed) was not a significant factor (boys: $\mathrm{F}=.1318, \mathrm{df}=2 / 12, \mathrm{p}>.05 ;$ girls: $\mathrm{F}=$ $1.76, \mathrm{df}=2 / 10, \mathrm{p}>.05)$. The results of a $t$ test comparing the performance of dyad trial time of the boys with the girls showed no significant difference between the two sexes $(t=0.629$, df $=26, p>.05)$.

The sharing-behavior data consisted of the number of marbles each child kept for himself out of the total number of the nine earned marbles. The males kept for themselves an average of 4.97 marbles or $55.19 \%$ of the marbles; the females kept for themselves an average of 4.9 marbles or $54.70 \%$ of the total number. The results of a $t$ test indicated there were no significant differences between the sexes $(t=.029$, $\mathrm{df}=26, \mathrm{p}>.05$ ).

The total number of trials on which the Ss kept more marbles than they gave to the second child was also calculated. The males retained more marbles on 29 out of 30 trials or $96.67 \%$ of the time, and the females retained more marbles on 19 out of 26 trials or $76.67 \%$ of the time, a difference significant at the $5 \%$ level $(z=2.22)$.

$$
\text { DISCUSSION }
$$

The results of the cooperative and noncooperative button presses showed that the children were using the cooperative switch a significantly greater number of times than the noncooperative. These data conflict with the results reported by Brotsky \& Thomas (1967), who failed to show differences between cooperative and noncooperative responses. In the Brotsky \& Thomas (1967) study, altholgh cooperative responses increased, noncooperative responses also increased. These data do support the earlier work of Azrin \& Lindsley (1956) who demonstrated the development of a cooperative response in children from 7 to 12 years old.

The significant sex and race variables for cooperative-noncooperative responses indicated that, on the cooperative response, males responded more than females and white children responded more than Negro children. Though there were differences in the number of emitted responses, this did not affect the time it took for two children to complete a cooperative task. From the results on the measure of total trial time, one can conclude that these preschool children, when paired in a cooperative task, do not respond any differently with a member of their own race than they do with a member of a different race. In addition, the males and females did not differ significantly from each other.

After the children earned nine marbles, each child was told to divide the marbles between himself and another child. Using both the definition of Handlon \& Gross (1959) and that of Ugurel-Semin (1952), the children's behavior could be defined as selfish. In this study, the children retained $55 \%$ of the marbles. There was no difference between the males and females in the percentage of marbles each group retained. When counting each trial as selfish or nonselfish, depending on whether the child kept more marbles for himself or gave more away, the males showed selfish behavior in $97 \%$ of the trials, while the females showed selfish behavior in only $77 \%$.

Because of the inconsistencies, the authors suggest that neither definition be used alone. Both definitions fail to give information on the actual number of shared items, one simply yielding information on the number of times a child keeps more items for himself and the other giving the percentage of items retained over trials.

It was observed in the present study and in the Ugurel-Semin (1952) study that when some children were given an odd number of items to divide, they first equally divided the items and then stated that one was extra. If, at this point, a child kept the extra item for himself, his behavior would be described as selfish. However, no indication is made that the child shared almost half his items. Additional research using an even number of items to share should add information to the question of children's sharing behavior.

\section{REFERENCES}

AZRIN, N. H, \& LINDSLEY, $O$. R. The reinforcement of cooperation between children. Journal of Abnormal \& Social Psychology, $1956,52,100-102$.

BROTSKY, S. J., \& THOMAS, K. Cooperative behavior in preschool children. Psychonomic Science, 1967, 9, 337-338.

HANDLON, B. J., \& GROSS, P. The development of sharing behavior. Journal of Abnormal \& Social Psychology, 1959, 59, 425-428.

UGUREL-SEMIN, R. Moral behavior and moral judgments of children. Journal of Abnormal \& Social Psychology, 1952, 47, 463-474.

WINER, B. J. Statistical principles in experimental design. New York: McGraw-Hill, 1962. NOTE

1. This research was supported in part by the Durham Education Improvement Program, Duke University, Durham, N.C. 27706. The authors are indebted to Dr. John Wasik, North Carolina State University, for his help with the statistical design and data analysis, and to Teresa Leonhardt, Durham Education Improvement Program, for her suggestions on the paper. 